\title{
Application and Exploration of Fast Gas Chromatography - Surface Acoustic Wave Sensor to the Analysis of Thymus Species
}

\author{
Se Yeon $\mathrm{Oh}^{1,2}$, Sung-Sun Park ${ }^{3}$, and Jongki Hong ${ }^{1}$ \\ ${ }^{1}$ College of Pharmacy, Kyung Hee University, Seoul 130-701, \\ ${ }^{2}$ Aroma Analytical Laboratory, KOSMO NF Co., Ltd. , Seoul 502-5, \\ ${ }^{3}$ Graduate School of Cultural Industry, Sungshin Women's University, Seoul 136-742, \\ South Korea
}

\section{Introduction}

Thymus is an aromatic and medicinal plant of increasing importance in horticulture and economics. Thymus is a genus of about 350 species of aromatic perennial herbs in the family Lamiaceae (mint family), and native to Europe, North Africa and Asia. Its essential oil has found diverse applications in pharmacy and medicine. Its volatile phenolic oil, for example thymol and carvacrol, has been reported to have antibacterial, antimycotic, antioxidative, and mammalian age delaying properties. Also thymus serves as a flavoring agent for a variety of food products and used as an antiseptic agent for its antimicrobial properties [13]. The content of essential oil varies drastically with climate, time of harvest and storage conditions [4-6].

For many years, GC and GC-MS have been used widely for the characterization of the volatile aroma components in thymus species. However, traditional GC method requires several routine isolation procedures including solvent extraction $[7,8]$, steam distillation $[9$, 10], and simultaneous distillation extraction [11]. These methods involve excessive manipulation of the sample, a very costly, time-consuming procedure, are limited in aroma correlation, and do not allow on-line measurements which may lead to inadequate results. Recently, headspace solid-phase microextraction (HS-SPME) as a successful solvent-free sampling technique has been introduced for purpose of aroma analysis [12, 13]. Especially, aroma analysis demands rapid and simple procedure, because new aroma components may arise from chemical and biochemical reactions promoted by heat and oxidation conditions. Also, aromas are usually composed of complex mixtures of many volatiles, human sensory evaluation by trained panelists is important in aroma analysis. However, it has many limitations which involve a very expensive, time-consuming procedure, and subjectiveness of expert. Therefore, the development in analytical method which provides rapid, simple, low-cost procedure and the clear relationship between their sensory impacts is one of the most desirable subjects in aroma chemistry.

A few years later, a new technique, based on the fast gas chromatography combined with uncoated high quartz surface acoustic wave sensor (GC/SAW, zNose) [14-17] appeared to be one of the suitable methods. Its principle has many similarities comparative to the human 
perception system. The advantages of GC/SAW include simplicity, real-time detection of volatiles, non-destructive, portability and lower costs in comparison to a portable GC-MS. Fast GC/SAW permits quantification and pattern recognition by fragrance pattern, called a VaporPrint derived from the frequency of a SAW sensor. Moreover, good sensitivity at the high picogram to nanogram level makes it possible to detect sensitive aroma materials quantitatively $[15,18]$. The method validation of GC/SAW and adaptability to a variety of applications were reported in our previous paper [18].

Statistical analysis methods including principal component analysis (PCA) have been successfully applied for the quality control and classification of various herbal medicines or aroma plants. PCA analysis and hierarchical clustering analysis (HCA) as pattern recognition analysis involves the discrimination of chromatographic data of herbal extracts or aroma plants with similar species $[19,20]$. Pattern recognition analysis based on the chromatographic data can predict and evaluate the quality control of aroma plants.

The aim of this study is to show the application and exploration of the developed GC/SAW methodology to the analysis of the volatile aroma composition profiles among thymus species in order to introduce this advantageous alternative analytical technique in pharmacy, medicine, and horticulture.

\section{Experimental}

\subsection{Materials}

Thymus (T. quinquecostotus, T. quinquecostotus var. japonica, T. mongolicus, T. serpyllum) plants grown nearby Pocheon city, Kyunggi-Do in South Korea were collected by sunny day sampling in September 2005. The geographical origins of T. quinquecostotus and its variety are from South Korea. T. mongolicus is in Northeastern Asia, and T. serpyllum is in Europe. The medicinal plant material consists of stem and leaves which are raw, elapsed for 5 days at $5{ }^{\circ} \mathrm{C}$ and air-dried for 13 days or 16 months. All standard chemicals of analytical grade were purchased from Sigma-Aldrich (St. Louis, Mo, USA) and Tokyo Kasei (Nihonbashi, Tokyo Japan). Organic solvents of a chromatographic grade were obtained from J .T. Baker. The commercially available carboxen-divinylbenzene-polydimethylsiloxane (CAR-DVBPDMS) SPME fiber (film thickness, 50/30 $\mu \mathrm{m}$ ) was purchased from Supelco (Bellefonte, PA, USA) and used.

\subsection{GC/SAW (zNose) description}

GC/SAW (4100 vapor analyzer, Electronic Sensor Technology, New Bury Park, USA) composed with the fast gas chromatograph and surface acoustic wave sensor is used to detect vapors of the volatile organic compounds. The GC/SAW is especially sensitive to low concentrations.

The uncoated piezo-electric quartz crystal SAW (Surface Acoustic Wave) sensor [14] represents a new class of GC detector. The specificity of the uncoated SAW sensor is based upon the temperature of the crystal surface and the vapor pressure characteristics of the condensates. At a given crystal temperature, analytes with dew points closer to the crystal temperature will interact and be detected better than those with dew points well above the SAW temperature. The high $\mathrm{Q}$ crystal is in contact with a thermoelectric element, which controls the temperature for cooling during vapor adsorption and for heating during cleaning of the crystal and operates by maintaining highly focused and resonant surface acoustic waves of $500 \mathrm{MHz}$ on its surface. 


\section{$2.3 \mathrm{GC} / \mathrm{SAW}$ analytical conditions and procedure}

About $1.0 \mathrm{~g}$ of each air-dried thymus sample was weighed into a $40-\mathrm{ml}$ glass vial sealed with a screw cap containing a Teflon/silicone septa. The capped vial was allowed to equilibrate with the headspace in the vial under the $60 \%$ humidity and $24^{\circ} \mathrm{C}$ for $1 \mathrm{~h}$ just before analysis. GC/SAW utilizes two steps to analyze vapors: the sampling process and the injection process. The headspace vapor is swept at $30 \mathrm{ml} / \mathrm{min}$ via a pump into the inlet, then the vapor passes through the valve where the compounds are adsorbed onto the Tenax trap inside the system. Switching the valve to the injection process causes helium gas to flow backwards through the Tenax trap and onto the column. During the injection process, the Tenax trap is heated rapidly to $200{ }^{\circ} \mathrm{C}$ to desorb the material. Details of this procedure were reported in our previous paper [18]. GC column was heated from $32{ }^{\circ} \mathrm{C}$ to $120^{\circ} \mathrm{C}$ at a rate of $3{ }^{\circ} \mathrm{C} / \mathrm{s}$ and the sampling time was $1 \mathrm{~s}$. Helium (99.999\%) was used as a carrier gas at 3.2 $\mathrm{ml} / \mathrm{min}$ (0.053 $\mathrm{ml} / \mathrm{s}) .6 \%$ cyanopropyl phenyl polydimethylsiloxane (DB-624, J\&W Scientific, Folsom, CA, USA, $1 \mathrm{~m} \times 0.25 \mathrm{~mm}$ i.d., $0.25 \mu \mathrm{m}$ film thickness) fused silica capillary column was used. The set-up temperatures were at $30^{\circ} \mathrm{C}$ for sensor, $130{ }^{\circ} \mathrm{C}$ for inlet port, and $110{ }^{\circ} \mathrm{C}$ for valve. Triplicate measurements per vial were carried out. All analytical procedures were completed within $30 \mathrm{~s}$. The shorter total time-to-result per sample allows several replicated analyses of a sample.

\subsection{Headspace solid-phase microextraction (HS-SPME)}

About $2.0 \mathrm{~g}$ of air-dried thymus sample was placed in $25-\mathrm{ml}$ vial sealed with an aluminum cap containing a Teflon / silicone septa. The capped vial was kept to equilibrate under the humidity of $60 \%$ and $24^{\circ} \mathrm{C}$ for $1 \mathrm{~h}$ before HS-SPME sampling. The carboxen-divinylbenzenepolydimethylsiloxane (CAR-DVB-PDMS) SPME fiber (film thickness, 50/30 $\mu \mathrm{m}$ ) was used because it was most efficient among the various types of fiber for most volatile organic compounds $[12,21]$. The SPME fiber was exposed to the headspace above the thymus sample vial at $24{ }^{\circ} \mathrm{C}$ for $1 \mathrm{~h}$. After adsorption, the SPME fiber was retracted from the sample vial and immediately inserted into the injection port of the GC-MS where thermal desorption was performed at $240{ }^{\circ} \mathrm{C}$ for $1 \mathrm{~min}$.

\subsection{GC-MS analysis}

The sample analysis was carried out with a Thermoquest-Finnigan ion trap GC-MS (Austin, Texas, USA) equipped with 6\% cyanopropyl phenyl polydimethylsiloxane (DB-624, J\&W, 30 $\mathrm{m} \times 0.25 \mathrm{~mm}$ i.d., $1.4 \mu \mathrm{m}$ film thickness) and a Hewlett-Packard 6890 Series GC system with an Agilent 5973N Mass Selective Detector (Agilent Technologies, Wilmington, DE, USA) equipped with 5\% phenyl polydimethylsiloxane (Ultra 2 column, Agilent, $25 \mathrm{~m} \times 0.25 \mathrm{~mm}$ i.d., $0.33 \mu \mathrm{m}$ film thickness). The oven temperature was initially maintained at $50{ }^{\circ} \mathrm{C}$ for 3 min and then programmed to $220^{\circ} \mathrm{C}$ for $5 \mathrm{~min}$ at a rate $5^{\circ} \mathrm{C} / \mathrm{min}$. Injector and transfer line, and quadrupole temperatures were set at $240{ }^{\circ} \mathrm{C}, 250{ }^{\circ} \mathrm{C}$, and $150{ }^{\circ} \mathrm{C}$, respectively. Helium $(99.999 \%)$ was used as a carrier gas at $1.0 \mathrm{ml} / \mathrm{min}$. The sample was injected under split mode (split ratio 1:30). The mass spectrometer was run in the electron impact (EI) mode with electron energy at $70 \mathrm{eV}$, scanning the 50.0-400.0 amu. The ion source temperatures of ion trap GC-MS and quadrupole GC-MS were maintained at $200{ }^{\circ} \mathrm{C}, 230{ }^{\circ} \mathrm{C}$, respectively. Triplicate measurements per vial were carried out. 


\subsection{Data analysis for pattern recognition}

Data transformation for pattern recognition was performed using MS Excel. Fifteen components were chosen based on the corresponding GC/SAW and HS-SPME-GC-MS profile. Especially, fifteen components such as a-pinene, camphene, $\beta$-myrcene, $p$-cymene, $\gamma$-terpinene, terpinolene, cis-sabinene hydrate, camphor, borneol, a-terpineol, thymol methyl ether, thymoquinone, thymol, $\beta$-caryophyllene and $\beta$-bisabolene were found as characteristic components in GC/SAW and HS-SPME-GC-MS profile. And then the response of each peak was applied from the triplicate measurements. Finally, pattern recognition techniques have been used for the discrimination of the materials. Principal component analysis (PCA) is a pattern recognition technique and statistical analysis. PCA was also carried out using MVSP. 3.1 version (Kovach Computing Service, Anglesey, Wales) in order to classify thymus species.

\section{Results and discussion}

\subsection{Identification of volatile herbal aroma compounds for air-dried for 13 days of thymus species by GC/SAW}

By using fast GC/SAW, volatile herbal aroma profiles for thymus species were obtained. The materials sequentially exit from the column and they land and stick on the SAW sensor. When an analyte adsorbs on the surface of the sensor, the frequency of SAW sensor is altered, which affects the detection signal in direct proportion to the amount of condensate. Fig. 1(A)-(E) shows chromatograms of volatile aroma compounds for air-dried for 13 days of thymus species. The area of each peak is correlated to its concentration and is expressed in frequency counts (Cts). The identification of each aroma compounds shown by GC/SAW was carried out by comparison with authentic standards and GC-MS analysis and their relative proportions ( $\%$ total amounts) are summarized in Table 1 . The herbal aroma components of thymus species consist mostly of monoterpene hydocarbons (a-pinene, camphene, $\beta$-myrcene, and terpinolene), oxygenated monoterpenes (cis-sabinene hydrate, camphor, borneol, a-terpineol, and thymoquinone), a monoterpene phenol (thymol), monoterpene phenol precursors ( $p$-cymene and $\gamma$-terpinene), a monoterpene phenol derivative (thymol methyl ether) and sesquiterpenes ( $\beta$-caryophyllene and $\beta$-bisabolene). The grouping of compounds has an important meaning as responsible for the characteristic aroma of thymus.

Fifteen compounds were identified, especially in T. quinquecostotus species, which are from Jeju and Mt Gaya in South Korea, the characteristic, distinctive components such as $p$-cymene $(26.4 \%, 24.2 \%)$, $\gamma$-terpinene $(10.3 \%, 10.5 \%)$, and active thymol $(29.0 \%, 33.1 \%)$ were constituted $65.7 \%, 67.8 \%$ of the total amounts, respectively. In addition, oxygenated monoterpenes such as cis-sabinene hydrate $(0.6 \%, 0.7 \%)$, camphor $(6.6 \%,-)$, borneol $(4.7 \%, 5.7 \%)$ and thymoquinone $(11.6 \%, 12.5 \%)$ were constituted $23.5 \%$ and $18.9 \%$ of the total amounts as the secondly most abundance, respectively. Lesser amounts of monoterpene hydrocarbons: a-pinene $(0.9 \%$, $0.8 \%)$, camphene $(0.9 \%,-), \beta$-myrcene $(5.3 \%, 3.3 \%)$, terpinolene $(1.2 \%, 2.4 \%)$ were constituted $8.3 \%$ and $6.5 \%$ of the total amounts, respectively, and $\beta$-caryophyllene $(2.5 \%, 6.8 \%)$ as sesquiterpene was also found. T. quinquecostotus var. japonica species is a variety of $T$. quinquecostotus and its geographical origin is Ulreung island in South Korea. $p$-Cymene (15.8\%), $\gamma$-terpinene $(9.0 \%)$, and thymol (33.5\%) were also found as characteristic components and constituted $58.3 \%$ of the total amounts. Also, oxygenated monoterpenes $(32.3 \%)$, monoterpene hydrocarbons (5.5\%), and sesquiterpenes (3.9\%) were found. 


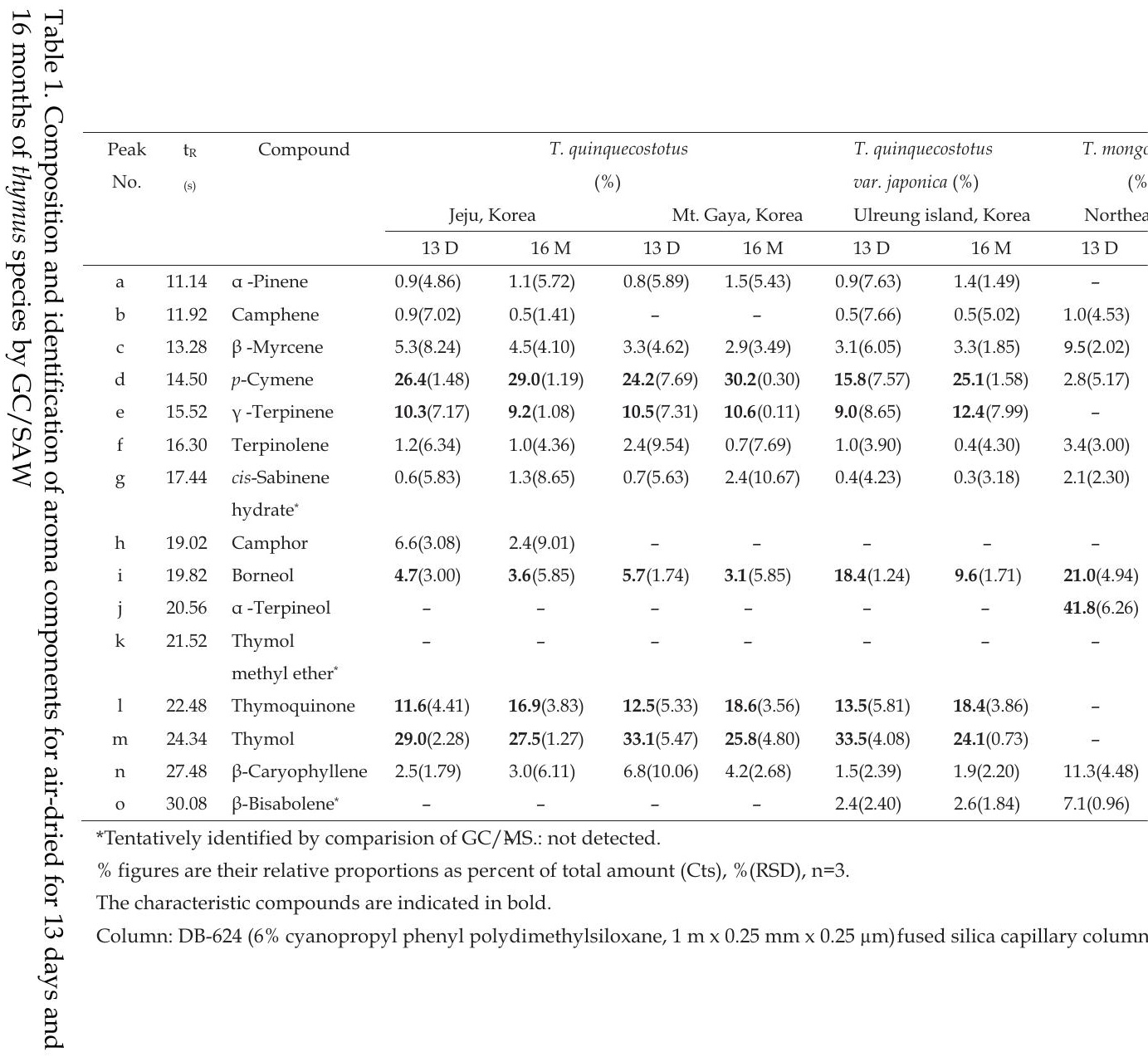


Generally, thymol, phenolic monoterpene, defines the essential oil quality because of its active pharmacological properties. It was reported that $\gamma$-terpinene and $p$-cymene are the precursors of phenolic monoterpenes such as thymol and carvacrol in T. vulgaris by Granger and Passet [22]. It was also proposed that $\gamma$-terpinene assumes an important role in the aromatization whose product is $p$-cymene. They reported that $p$-cymene is the precursor of thymol by hydroxylation in T. vulgaris L. plant [23]. Moreover, the concentration of $p$ cymene and $\gamma$-terpinene are found to vary in coincidence with the variation in their corresponding phenolic monoterpene products [24] and $\gamma$-terpinene decreases its concentration and $p$-cymene increases in the essential oil [25].

In T. mongolicus species (the origin of Northeastern Asia), active phenolic monoterpene (thymol) and its corresponding monoterpene hydrocarbon precursor ( $\gamma$-terpinene) were not found, whereas oxygenated monoterpenes, such as borneol (21.0\%), a-terpineol $(41.8 \%)$, were identified as characteristic predominant compounds and constituted $62.8 \%$ of the total amounts. T. serpyllum species (the origin of Europe) contain almost the same chemical components with those of T. quinquecostotus. Especially, a monoterpene phenol derivative (thymol methyl ether: $12.7 \%$ ) was only found as characteristic component. It was tentatively identified by comparison of its GC-MS data, because its reference standard is not commercially available.

\subsection{Discrimination of thymus species using VaporPrint image based on GC/SAW}

By comparing the relative contents, chemical composition for characteristic components of air-dried for 13 days of T. quinquecostotus species which are originated from Jeju and Mt. Gaya in South Korea were almost same: the active monoterpene phenol (thymol: $29.0 \%$, $33.1 \%)$, its corresponding precursors ( $p$-cymene: $26.4 \%, 24.2 \%$, $\gamma$-terpinene: $10.3 \%, 10.5 \%$ ) and oxygenated monoterpenes (borneol: $4.7 \%, 5.7 \%$, thymoquinone: $11.6 \%, 12.5 \%$ ). It is interesting to note that the components found in the same species of different geographical origin in same country are almost same. Also, the proportion of such components is same.

The GC/SAW provides a visually recognizable fragrance pattern (VaporPrint image) derived from the frequency of SAW sensor. This image is created by transforming the time variable to a radial angle with the beginning and end of the analysis. This image transfers the olfactory response to a visual response [18]. These fragrance images are a useful for comparing delicate differences of various thymus species for species identification. The fragrance patterns for air-dried for 13 days of thymus species are shown in Fig. 1(A')-(E'). As shown in Fig. 1( $\left.\mathrm{A}^{\prime}\right)$ and $\left(\mathrm{B}^{\prime}\right)$, these same species present almost same fragrance patterns.

In its variety species (the origin of Ulreung island in South Korea), the most components are similar in chemical compositions between original and its variety, specific components which are $p$-cymene (original species: Jeju 26.4\%; Mt. Gaya 24.2\%, its variety species: $15.8 \%$ ), borneol (original species: Jeju 4.7\%; Mt. Gaya 5.7\%, its variety species: $18.4 \%$ ) were shown a different compositions. Also, $\beta$-bisabolene $(2.4 \%)$ was found additionally in variety species. Therefore, such differences seem to result in a small differences in fragrance pattern (Fig. 1( $\left.A^{\prime}\right)$ and $\left(C^{\prime}\right)$ ). T. serpyllum species (the origin of Europe) contain almost same chemical components with those of T. quinquecostotus, but show a substantial different chemical compositions: active thymol (T. serpyllum : 34.1\%, T. quinquecostotus : Jeju 29.0\%; Mt. Gaya 33.1\%), active thymol precursors (T. serpyllum : 20.0\%, T. quinquecostotus : Jeju 36.7\%; Mt. Gaya 34.7\%), oxygenated monoterpenes, (T. serpyllum : 14.9\%, T. quinquecostotus : Jeju 23.5\%; Mt. Gaya $18.9 \%$ ), and sesquiterpenes (T. serpyllum : 9.3\%, T. quinquecostotus : Jeju 2.5\%; Mt. Gaya 6.8\%) were found 

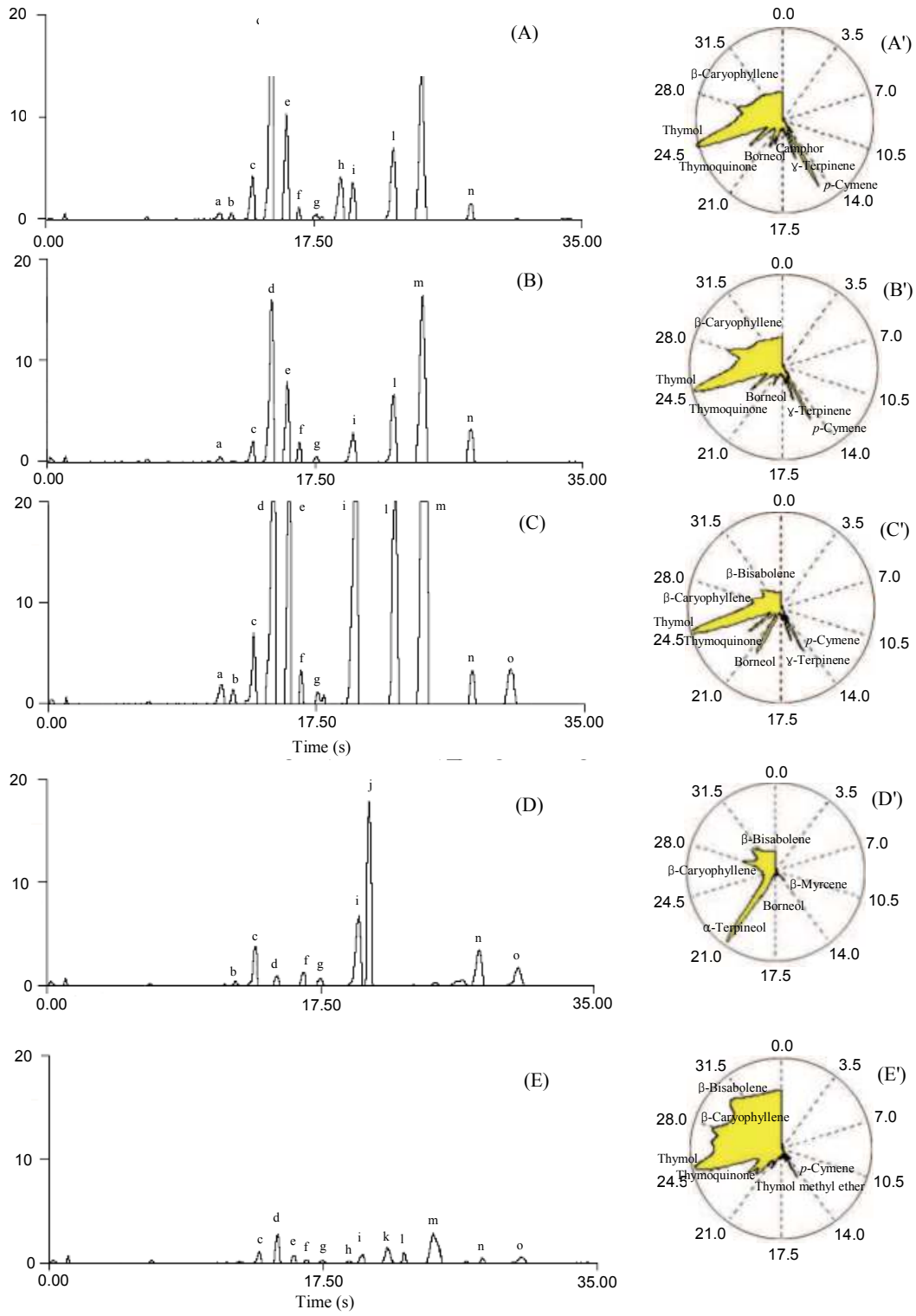

Fig. 1. Comparison of chromatograms for various thymus species by GC/SAW. (A) T. quinquecostotus, Jeju, Korea; (B) T. quinquecostotus, Mt. Gaya, Korea; (C) T. quinquecostotus var. japonica, Ulreung island, Korea; (D) T. mongolicus, Northeastern Asia; (E) T. serphyllum, Europe; (A' )-(E') their corresponded fragrance patterns using VaporPrint.

Peak identities: $a$, $a$-Pinene; $b$, Camphene; $c, \beta$-Myrcene; $d, p$-Cymene; e, $\gamma$-Terpinene; $f$, Terpinolene; g, cis-Sabinene hydrate; $h$, Camphor; $\mathrm{i}$, Borneol; $\mathrm{j}$, a-Terpineol; $\mathrm{k}$, Thymol methyl ether; 1 , Thymoquinone; $\mathrm{m}$, Thymol; $\mathrm{n}, \beta$-Caryophyllene; $\mathrm{o}, \beta$-Bisabolene. 
, respectively. Therefore, distinctive differences seem to result in a substantial differences in fragrance pattern (Fig. 1(E')).

As a result, it turned out that each species has own characteristic fragrance pattern owing to its own chemical compositions and its own characteristic fragrance patterns are conducive to species identification.

\subsection{Comparison of GC/SAW and HS-SPME-GC-MS method for air-dried for 13 days of thymus species}

The compositions of aroma compounds of thymus species extracted by HS-SPME using CAR/DVB/PDMS fiber and then analyzed by GC-MS are presented in Table 2. Their GCMS total ion chromatograms are shown in Fig. 2. The alphabetic numbers of peaks shown in Fig. 2 correspond to the numbers indicated in GC/SAW chromatograms (Fig. 1). These results are comparable to those given by GC/SAW, including the characteristic components and chemical composition. Fifty-four compounds were detected by HS-SPME-GC-MS.

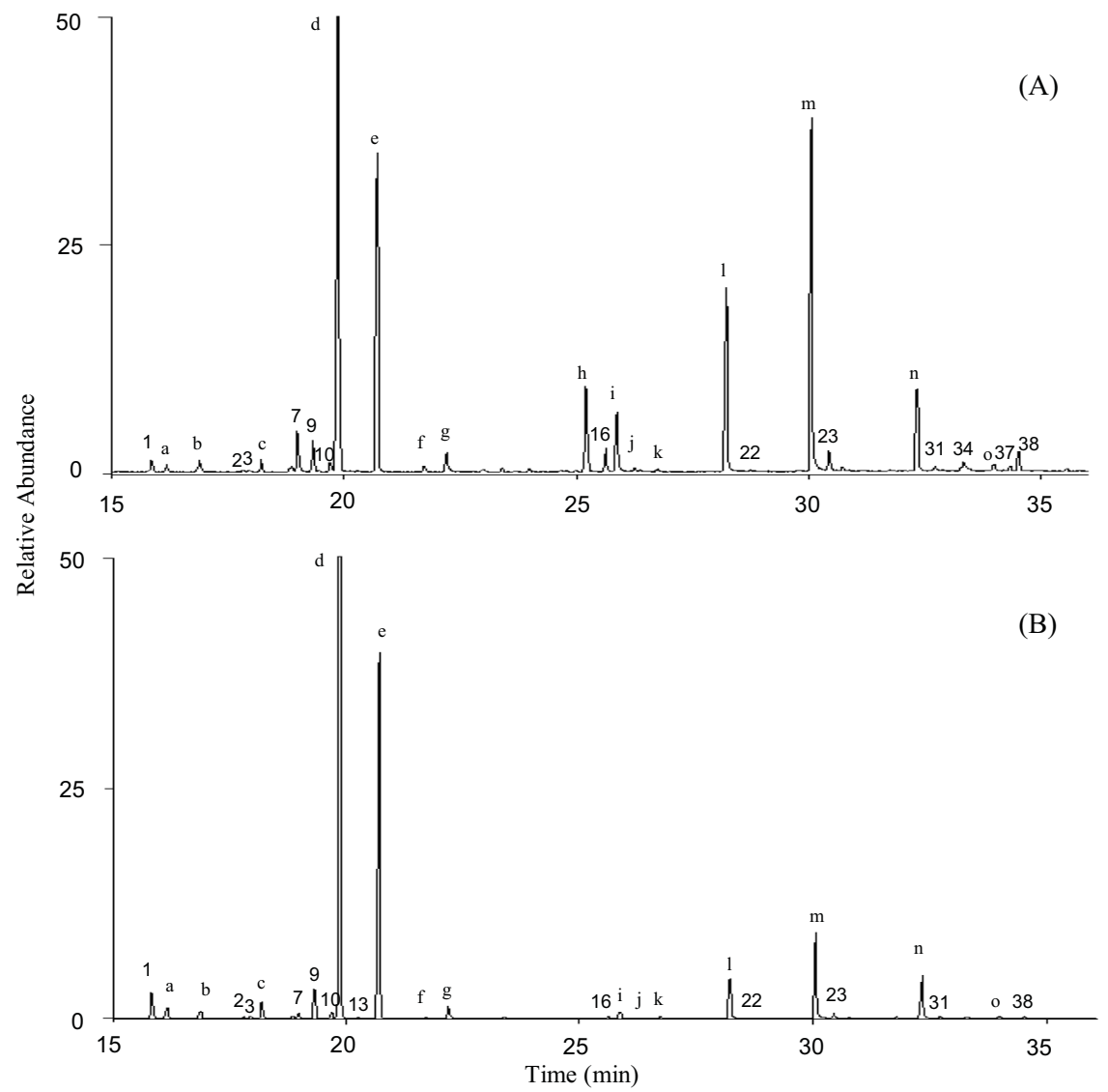

Fig. 2. Comparison of chromatograms for various thymus species by HS-SPME-GC-MS. (A) T. quinquecostotus, Jeju, Korea; (B) T. quinquecostotus, Mt. Gaya, Korea; (C) T. quinquecostotus var. japonica, Ulreung island, Korea; (D) T. mongolicus, Northeastern Asia; (E) T. serphyllum, Europe. 

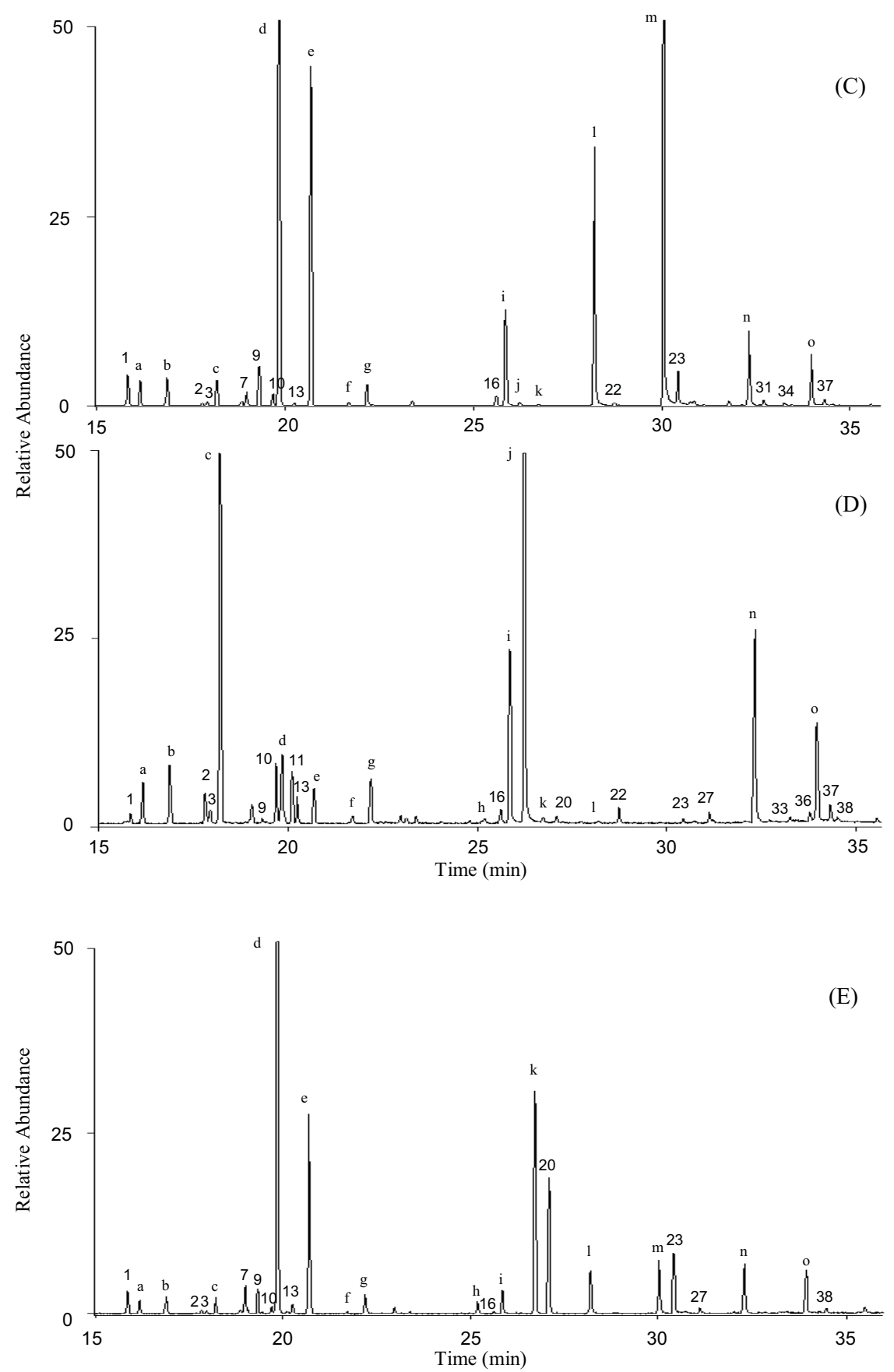

Fig. 2. Continued 
As shown in Table 3, characteristic components and analytical tendency for air-dried for 13 days of thymus species detected by GC/SAW and HS-SPME-GC-MS are similar, but the abundance ratios between these two methods are different. In T. quinquecostotus species, monoterpene phenols (thymol, carvacrol) and monoterpene phenols precursors ( $p$-cymene, $\gamma$-terpinene) were also dominant $(76.0 \%)$ like GC/SAW (66.8\%). But, the amounts of total monoterpene phenols are $11.7 \%$ by HS-SPME-GC-MS, $31.1 \%$ by GC/SAW and monoterpene phenols precursors are $64.3 \%$ by HS-SPME-GC-MS, $35.7 \%$ by GC/SAW. In comparison of T. quinquecostotus var. japonica species and its original species, these results show similar analytical tendency with GC/SAW. For instance, $p$-cymene decreases from $46.3 \%$ to $22.2 \%$ by HS-SPME-GC-MS and from $\mathbf{2 5 . 3} \%$ to $15.8 \%$ by GC/SAW (an average value is indicated in bold) (Table 1 and 2). While oxygenated monoterpene increases from $11.3 \%$ to $17.6 \%$ by HS-SPME-GC-MS and from $21.2 \%$ to $32.3 \%$ by GC/SAW. In T. mongolicus species, the characteristic and dominant components are borneol and a-terpineol in similar to the results by GC/SAW. But, the amounts of borneol and a-terpineol are $8.0 \%$ and $31.0 \%$ by HS-SPMEGC-MS; $21.0 \%$ and $41.8 \%$ by GC/SAW, respectively (Table 1 and 2). Interestingly, the significant amount of thymol methyl ether and carvacrol methyl ether which are not almost found in other species were found in T. serpyllum species. The amounts are $20.5 \%$ by HSSPME-GC-MS and $12.7 \%$ by GC/SAW.

\subsection{Compositions of volatile herbal aroma compounds of thymus species of elapsed for 16 months by GC/SAW}

The compositions of volatile herbal aroma compounds of thymus species of elapsed for 16 months extracted by GC/SAW are presented in Table 1. As a result, according to elapse for 16 months, there are slightly differences in the relative quantities of their characteristic constituents than those of 13 days: in T. quinquecostotus species and its variety, active thymol precursor $p$-cymene increases from $25.3 \%$ to $29.6 \%$ and from $15.8 \%$ to $25.1 \%$, respectively, whereas active thymol decreases from $31.1 \%$ to $26.7 \%$, $33.5 \%$ to $24.1 \%$, respectively (an average value is indicated in bold). However, for $T$. serpyllum species, there appears distinctive differences compared to those dried for 13 days: $p$-cymene also increases from $15.8 \%$ to $30.4 \%$ and thymol substantially decreases from $34.1 \%$ to $1.1 \%$, while thymol precursor $\gamma$-terpinene is not found and sesquiterpene $\beta$-bisabolene increases 2 times. In $T$. mongolicus species, a-terpineol as the characteristic and dominant component also slightly decreases from $41.8 \%$ to $35.9 \%$.

\subsection{Principal component analysis for GC/SAW and HS-SPME-GC-MS responses of thymus species}

Fig. 3(A) shows principal component analysis (PCA) for GC/SAW responses of air-dried for 13 days and 16 months of thymus species. PCA were carried out using MVSP. 3.1 version in order to classify the thymus species. As a result, a good classification among four different species: T. quinquecostotus, T. quinquecostotus var. japonica, T. mongolicus, and T. serpyllum was obtained. Additionally, the classification of same species which are from different geographical origin in same country, classification of original species and its variety for $T$. quinquecostotus, classification as an air-drying term for 13 days and 16 months for $T$. quinquecostotus showed good results. In these results, it turned out that discrimination of various thymus species by using VaporPrint image based on GC/SAW are very clear, which was reproducible data points shown in Fig. 3(A). 


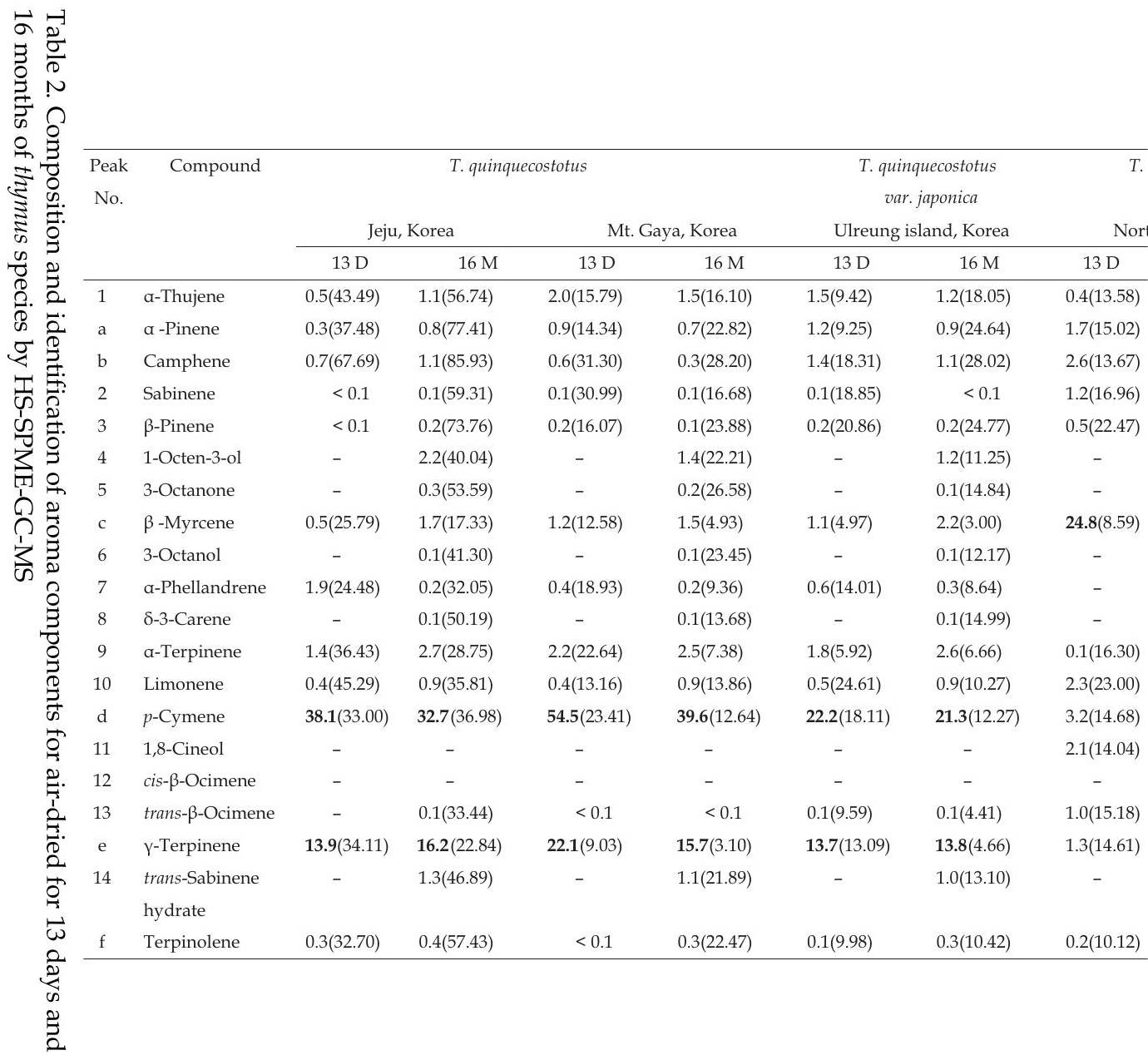




\begin{tabular}{|c|c|c|c|c|c|c|c|c|}
\hline \multirow[t]{3}{*}{$\begin{array}{l}\text { Peak } \\
\text { No. }\end{array}$} & \multirow[t]{3}{*}{ Compound } & \multicolumn{4}{|c|}{ T. quinquecostotus } & \multicolumn{2}{|c|}{$\begin{array}{c}\text { T. quinquecostotus } \\
\text { var. japonica }\end{array}$} & T. \\
\hline & & \multicolumn{2}{|c|}{ Jeju, Korea } & \multicolumn{2}{|c|}{ Mt. Gaya, Korea } & \multicolumn{2}{|c|}{ Ulreungdo, Korea } & Nortl \\
\hline & & $13 \mathrm{D}$ & $16 \mathrm{M}$ & $13 \mathrm{D}$ & $16 \mathrm{M}$ & $13 \mathrm{D}$ & $16 \mathrm{M}$ & $13 \mathrm{D}$ \\
\hline g & $\begin{array}{l}\text { cis-Sabinene } \\
\text { hydrate }\end{array}$ & $1.0(51.74)$ & $0.3(49.71)$ & $1.0(16.72)$ & $0.3(26.10)$ & 1.1(15.47) & $0.3(11.25)$ & $1.8(7.31)$ \\
\hline 15 & Linalool & - & - & - & - & - & - & - \\
\hline $\mathrm{h}$ & Camphor & $4.5(41.59)$ & $2.7(63.50)$ & - & - & - & $<0.1$ & $0.3(5.47)$ \\
\hline 16 & a-Terpinen-4-ol & $1.1(45.81)$ & $0.6(47.48)$ & $0.1(10.29)$ & $0.6(18.66)$ & $0.4(17.14)$ & $0.7(11.71)$ & $0.6(12.86)$ \\
\hline $\mathrm{i}$ & Borneol & $3.2(43.16)$ & $2.0(50.19)$ & $0.5(21.20)$ & 1.1(29.97) & $4.6(4.07)$ & $5.6(15.77)$ & $8.0(3.26)$ \\
\hline 17 & p-Cymen-8-ol & - & $0.1(65.86)$ & - & $0.1(32.27)$ & - & $<0.1$ & - \\
\hline$j$ & a-Terpineol & $\mathrm{t}$ & $0.1(58.05)$ & $\mathrm{t}$ & $0.1(17.27)$ & $0.1(28.90)$ & $0.2(76.32)$ & $31.0(9.41)$ \\
\hline 18 & cis-Dihydrocarvone & - & $0.1(78.32)$ & - & $<0.1$ & - & $0.1(41.41)$ & - \\
\hline k & $\begin{array}{l}\text { Thymol- } \\
\text { methyl ether* }\end{array}$ & $0.1(39.53)$ & $0.7(15.22)$ & $0.1(9.00)$ & $0.7(15.22)$ & $t$ & - & $0.2(24.30)$ \\
\hline 19 & Isoterpinolene & - & $0.1(42.74)$ & - & $0.1(29.69)$ & - & $0.2(25.00)$ & - \\
\hline 20 & $\begin{array}{l}\text { Carvacrol- } \\
\text { methyl ether* }\end{array}$ & - & - & - & - & - & - & $0.2(15.35)$ \\
\hline 21 & L-carvone & - & - & - & - & - & $0.1(13.69)$ & - \\
\hline 1 & Thymoquinone & $8.2(43.35)$ & $10.4(59.57)$ & $3.0(13.81)$ & $10.7(27.19)$ & $11.3(5.91)$ & $13.2(9.43)$ & $0.1(18.86)$ \\
\hline 22 & Bornyl acetate & $<0.1$ & - & $\mathrm{t}$ & - & $0.1(14.48)$ & - & $0.6(7.83)$ \\
\hline $\mathrm{m}$ & Thymol & $15.8(22.42)$ & $13.0(38.93)$ & $6.4(7.71)$ & $11.4(7.75)$ & $29.9(11.43)$ & $23.4(4.79)$ & - \\
\hline 23 & Carvacrol & $0.9(32.29)$ & $0.9(47.45)$ & $0.3(17.45)$ & $0.8(15.69)$ & $1.5(6.63)$ & $1.7(6.52)$ & $0.2(14.18)$ \\
\hline 24 & Thymyl acetate & - & - & - & - & - & $0.3(10.21)$ & - \\
\hline 25 & $\begin{array}{l}\text { Hydroxy- } \\
\text { thymoquinone }\end{array}$ & - & $0.2(81.71)$ & - & $0.3(54.28)$ & - & - & - \\
\hline 26 & a-Copaene & - & - & - & - & - & - & - \\
\hline
\end{tabular}




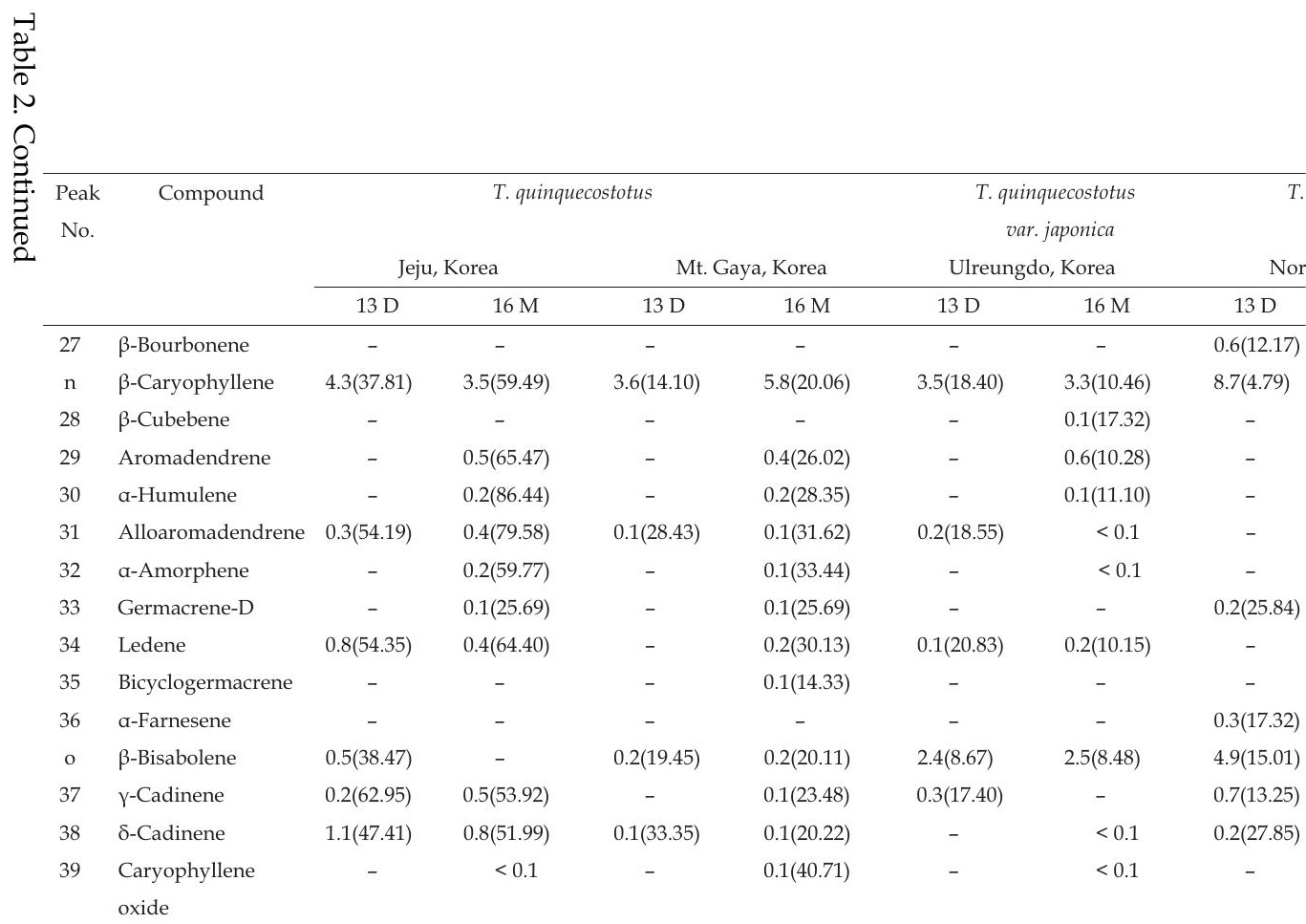

* Tentatively identified by comparision of MS data with those of library. -: not detected, $\mathrm{t}:<0.05 \%$.

$\%$ figures are their relative proportions as percent of total area , \%(RSD), $n=3$.

The characteristic compounds are indicated in bold.

DB-624 column was used for analysis of air-dried materials for 13 days and DB- 5 column was used for analysis of air-dried 


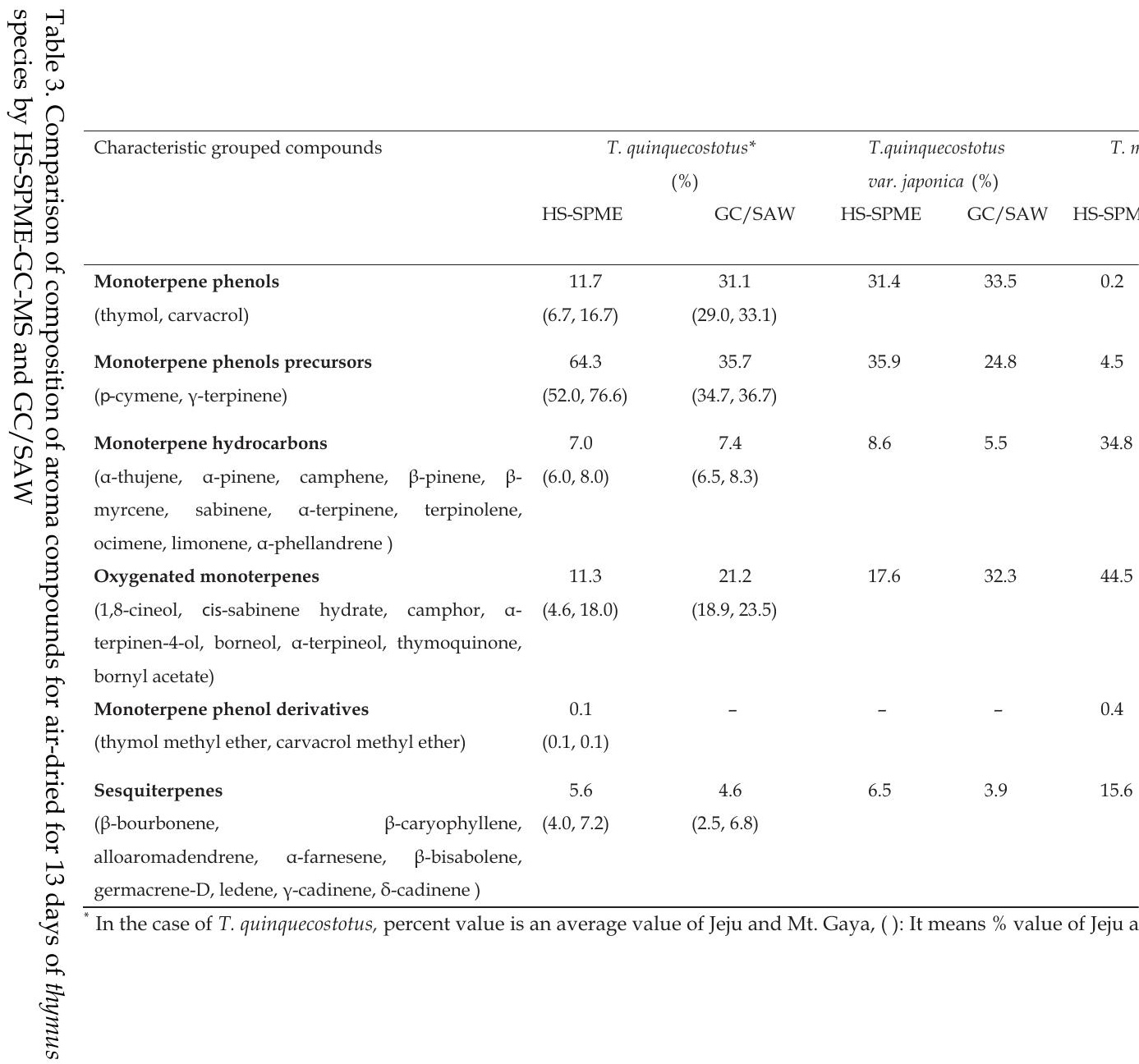


Fig. 3(B), (B') shows PCA for HS-SPME-GC-MS responses of air-dried for 13 days and 16 months of thymus species. As a result, a good classification among species of completely different chemotypes was obtained. But, the classification of T. quinquecostotus which are same species of different geographical origin in same country (from Jeju and Mt. Gaya in South Korea), classification of original species and its variety for T. quinquecostotus, grouped as an air-drying term 13 days and 16 months for T. quinquecostotus appeared to be quite lower than those achieved by GC/SAW.

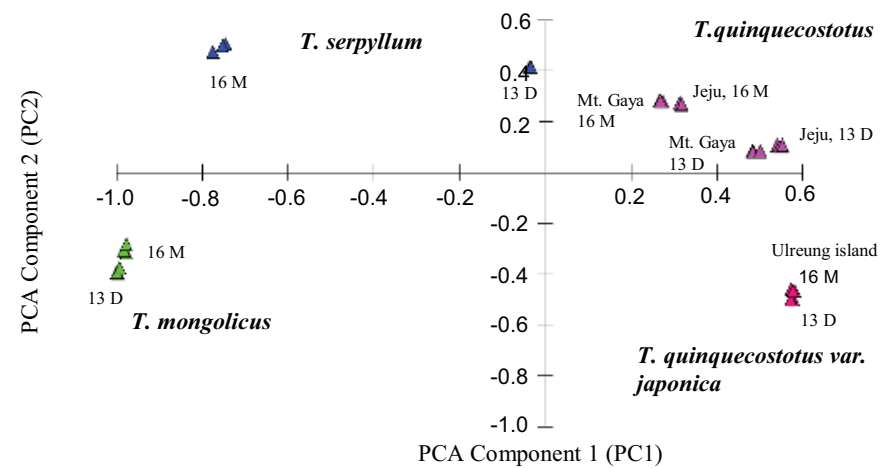

(A)

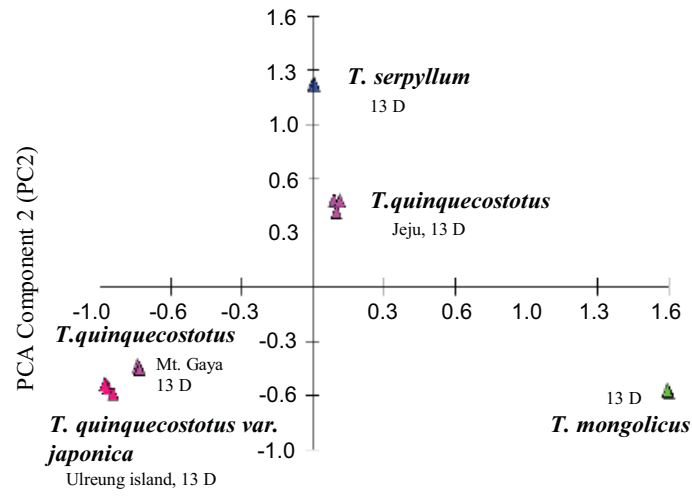

PCA Component $1(\mathrm{PC} 1)$
(B)

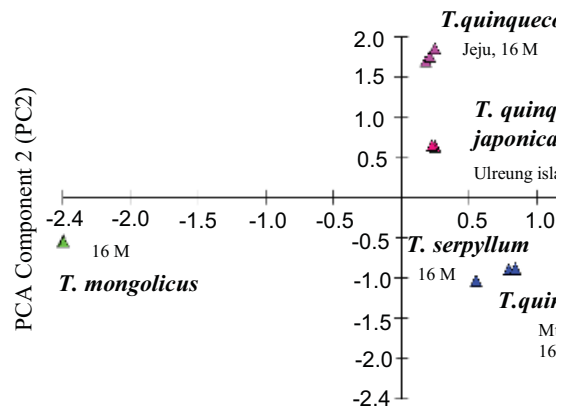

PCA Component 1 (PC1)

Fig. 3. Comparison of principal component analysis for GC/SAW (A) and HS-SPME-GC-MS (B), (B') responses of thymus species. (A) air-dried 13 days and 16 months by GC/SAW; (B) air-dried 13 days by Thermoquest-Finnigan ion trap GC-MS (Austin, Texas, USA) equipped with $6 \%$ cyanopropyl phenyl polydimethylsiloxane (DB-624, J\&W, $30 \mathrm{~m} \times 0.25$ mm i.d., $1.4 \mu \mathrm{m}$ film thickness); (B') air-dried 16 months by Hewlett-Packard 6890 Series GC system with an Agilent 5973N Mass Selective Detector (Agilent Technologies, Wilmington, DE, USA) equipped with $5 \%$ phenyl polydimethylsiloxane (Ultra 2 column, Agilent, $25 \mathrm{~m} \mathrm{x}$ $0.25 \mathrm{~mm}$ i.d., $0.33 \mu \mathrm{m}$ film thickness). 


\subsection{Changes of composition of aroma compounds according to elapse for $\mathrm{T}$. quinquecostotus var. japonica by GC/SAW}

Fig. 4 shows chromatograms of volatile aroma compounds according to elapse for $T$. quinquecostotus var. japonica by GC/SAW. The changes of composition of their volatile aroma compounds are summarized in Table 4.
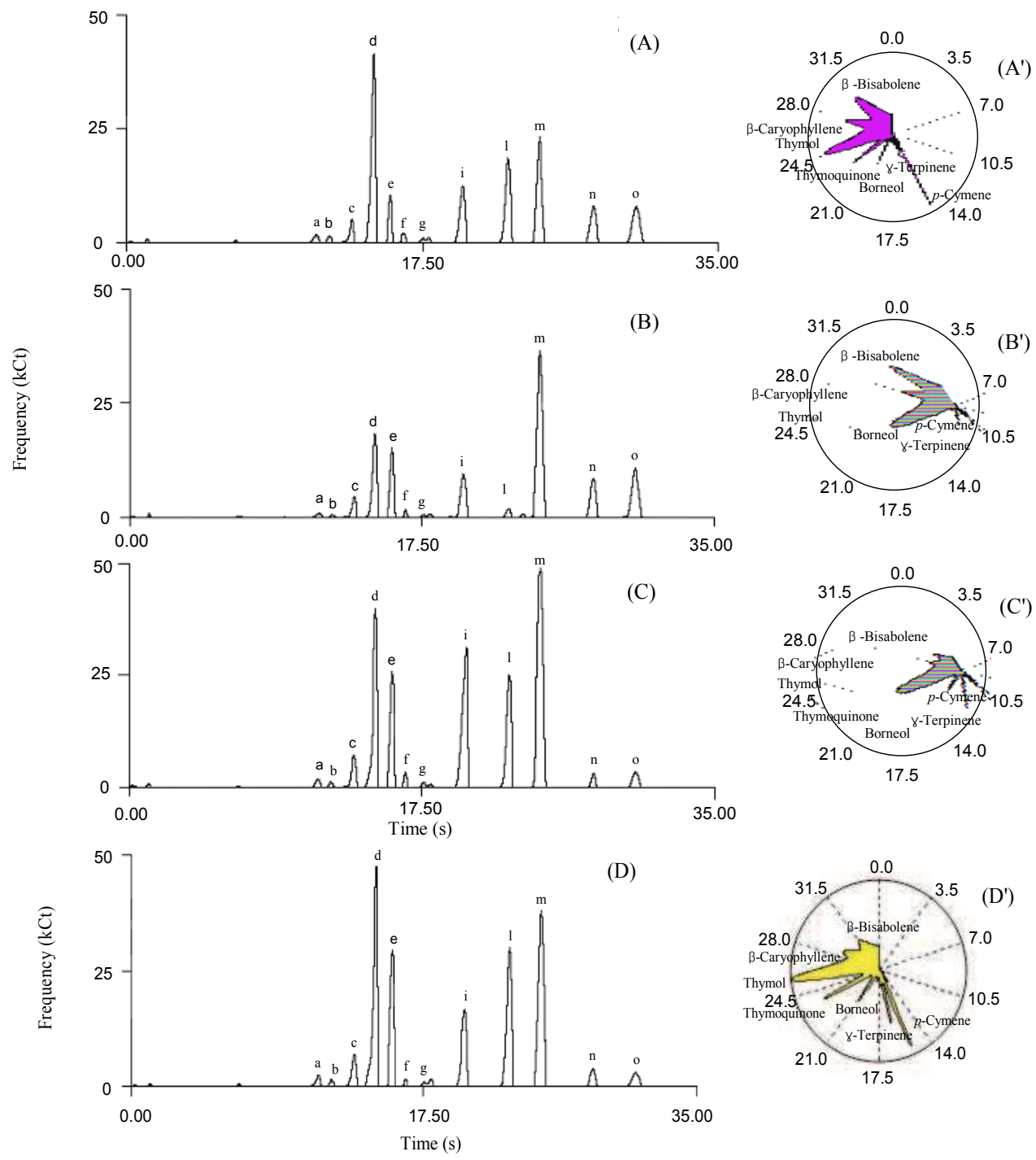

Fig. 4. Changes of composition of aroma compounds according to elapse for

T.quinquecostotus var. japonica by GC/SAW. (A) fresh raw; (B) elapsed for 5 days at $5^{\circ}$ C; (C) air-dried for 13 days at room temperature; (D) air-dried for 16 months at room temperature; $\left(\mathrm{A}^{\prime}\right)-\left(\mathrm{D}^{\prime}\right)$ their corresponded fragrance patterns using VaporPrint. 


\begin{tabular}{|c|c|c|c|c|c|c|}
\hline \multirow[t]{3}{*}{$\begin{array}{c}\text { Peak } \\
\text { No. }\end{array}$} & \multirow[t]{3}{*}{$\begin{array}{l}t_{R} \\
\text { (s) }\end{array}$} & \multirow[t]{3}{*}{ Components } & \multicolumn{4}{|c|}{$\begin{array}{l}\text { Thymus-quinquecostotus var. japonica } \\
\text { (Ulreung island) }\end{array}$} \\
\hline & & & Rawa $^{\mathrm{a}}$ & 5 Days ${ }^{b}$ & 13 Daysc & 16 Months ${ }^{\mathrm{d}}$ \\
\hline & & & & $\%$ & $\%$ & $\%$ \\
\hline a & 11.140 & a -Pinene & $1.3(8.20)$ & $0.7(4.21)$ & $0.9(7.63)$ & $1.4(1.49)$ \\
\hline $\mathrm{b}$ & 11.920 & Camphene & $0.8(2.53)$ & $0.4(1.75)$ & $0.5(7.66)$ & $0.5(5.02)$ \\
\hline c & 13.280 & $\beta$-Myrcene & $3.5(5.90)$ & $3.5(3.86)$ & $3.1(6.05)$ & $3.3(1.85)$ \\
\hline $\mathrm{d}$ & 14.500 & $p$-Cymene & $25.5(6.24)$ & $13.6(4.83)$ & 15.8(7.57) & 25.1(1.58) \\
\hline e & 15.520 & $\gamma$-Terpinene & $5.2(4.98)$ & 10.2(3.95) & $9.0(8.65)$ & 12.4(7.99) \\
\hline $\mathrm{f}$ & 16.300 & Terpinolene & $1.1(2.70)$ & $0.7(2.64)$ & $1.0(3.90)$ & $0.4(4.30)$ \\
\hline g & 17.440 & $\begin{array}{l}\text { cis-Sabinene } \\
\text { hydrate }\end{array}$ & $0.3(8.68)$ & $0.3(5.22)$ & $0.4(4.23)$ & $0.3(3.18)$ \\
\hline $\mathrm{h}$ & 19.020 & Camphor & - & - & - & - \\
\hline $\mathrm{i}$ & 19.820 & Borneol & $10.5(2.80)$ & 9.1(3.65) & 18.4(1.24) & $9.6(1.71)$ \\
\hline $\mathrm{j}$ & 20.560 & a -Terpineol & - & - & - & - \\
\hline k & 21.520 & $\begin{array}{l}\text { Thymol methyl } \\
\text { ether }\end{array}$ & - & - & - & - \\
\hline 1 & 22.480 & Thymoquinone & 14.9(3.35) & $1.6(0.70)$ & 13.5(5.81) & $18.4(3.86)$ \\
\hline $\mathrm{m}$ & 24.340 & Thymol & 20.4(1.65) & $37.4(5.37)$ & $33.5(4.08)$ & 24.1(0.73) \\
\hline $\mathrm{n}$ & 27.480 & $\beta$-Caryophyllene & $7.1(2.46)$ & $8.8(8.92)$ & $1.5(2.39)$ & $1.9(2.20)$ \\
\hline o & 30.080 & $\beta$-Bisabolene & $9.4(5.03)$ & $13.7(5.19)$ & $2.4(2.40)$ & $2.6(1.84)$ \\
\hline
\end{tabular}

Table 4 . Change of composition of volatile aroma compounds according to elapse for T.quinquecostotus var. japonica by GC/SAW

a Fresh sample, it was analyzed as soon as possible after it was picked.

b It was elapsed for 5 days at $5^{\circ} \mathrm{C}$.

c It was dried for 13 days at room temperature.

dIt was dried for 16 months at room temperature

In the raw sample which are prepared as soon as possible after it was picked, monoterpene phenol (thymol: $20.4 \%$ ) is lower than its corresponding precursor ( $p$-cymene, $\gamma$-terpinene: $30.7 \%$ ). Whereas, in the case of two samples which are elapsed for 5 days at $5{ }^{\circ} \mathrm{C}$ and airdried for 13 days at room temperature, active thymol $(33.5 \% \sim 37.4 \%)$ is higher than its corresponding precursor $(23.8 \% \sim 24.8 \%)$. Additionally, thymoquinone (13.5\%), borneol $(18.4 \%)$ in 13 days sample increased than those of 5 days sample. After elasping for 16 months, the concentration of active thymol (24.1\%) and borneol (9.6\%) considerably decreased, whereas thymoquinone $(18.4 \%)$ increased in high intensity.

As these results, they also show some interesting characteristic feature for the influence of air-drying on the volatile aroma compositions. In the aspect of pharmacological effects, it was found that active monoterpene phenol (thymol) reaches its highest concentrations after it was dried for 5 days or 13 days, which is much higher than in fresh or over-dried for a long times.

\section{Conclusion}

On the basis of this study, it is concluded that the GC/SAW analytical method shows high speed detection within ten seconds, a relatively high reproducibility compared with HSSPME method, simplicity, and making it possible to detect sensitive aroma materials 
quantitatively. It also enables to discriminate the botanical and geographical origin of thymus species by recognizable fragrance pattern analysis.

As a result, a new methodology by GC/SAW can serve as an alternative analytical technique for the analysis of discrimination of thymus species that provides second unit analysis, simple, highly sensitive analytical method, and fragrance pattern recognition compared to the conventional HS-SPME-GC-MS technique. In addition, it would be a first report to deal with the volatile herbal actual compositions and discrimination of thymus species by GC/SAW and will be applied to a variety of applications.

\section{References}

[1] G. Sachetti, S. Maietti, M. Muzzoli, M. Scaglianti, S. Manfredini, M. Radice, R. Bruni, Food Chem., 91 (2005) 621.

[2] J. Mastelić, I. Jerković, Food Chem. 80 (2003) 135.

[3] S.J. Lee, K. Umano, T. Shibamoto, K.G. Lee, Food Chem. 91 (2005) 131.

[4] P.H. Gouyon, Ph. Vernet, J.L. Guillerm, G. Valdeyron, Heredity 57 (1986) 59.

[5] M.D. Guillén, M.J. Manzanus, Food Chem. 63 (1998) 373.

[6] R. Venskutonis, L. Poll, M. Larsen, Flavour Fragrance J. 11 (1996) 123.

[7] F. Diemer, J.C. Caissard, S. Moja, J.C. Chalchat, F. Jullien, Plant Physiol. Biochem. 39 (2001) 603.

[8] M. Zimmermann, P. Schieberle, Eur. Food Res. Technol. 211 (2000) 175.

[9] G.B. Nickerson, S.T. Likens, J. Chromatogr. 21 (1966) 1.

[10] M.C. Díaz-Maroto, M.S. Pérez-Coello, M.D. Cabezudo, J. Chromatogr. A 947 (2002) 23.

[11] G. Suvarnalatha, M.S. Narayans, G.A. Ravishandar, L.V. Venkataraman, J. Sci. Food Agric. 66 (1994) 439.

[12] C. Bicchi, S. Drigo, P. Rubiolo, J. Chromatogr. A 892 (2000) 469.

[13] M. Kovaćević, M. Kać, J. Chromatogr. A 918 (2001) 159.

[14] E.J. Staples, Abstr. Pap. Am. Chem. 219 (2000) 236.

[15] E.J. Staples, J. Acoust. Soc. Am. 108 (2000) 2495.

[16] M. Kunert, A. Biedermann, T. Koch, W. Boland, J. Sep. Sci. 25 (2002) 677.

[17] J. Lammertyn, Els A. Veraverbeke, J. Irudayaraj, Sens. Actuators B 98 (2004) 54.

[18] S.Y. Oh, H.D. Shin, S.J. Kim, J. Hong, J. Chromatogr. A 1183 (2008) 170.

[19] M.K. Lee, Y.M. Ahn, K.R. Lee, J.H. Jung, J. O.S. Jung, J. Hong, Anal. Chim. Acta 633 (2009) 271.

[20] M.H. Chun, E.K. Kim, K.R. Lee, J.H. Jung, J. Hong, Microchem. J. 95 (2010) 31.

[21] D. Zabaras, S.G. Wyllie, Flavour Fragr. J. 16 (2001) 411.

[22] R. Granger and J. Passet, Phytochemistry 112 (1973) 1683.

[23] A.J. Poulose, R. Croteau, Arch. Biochem. Biophys. 187 (1978) 307.

[24] M. Hudaib, E. Speroni, A.M. Di Pietra, V. Cavrini, J. Pharm. Biomed. Anal. 29 (2002) 691.

[25] M.J. Jordán, R.M. Martínez, K.L. Goodner, E.A. Baldwin, J.A. Sotomayor, Ind. Crops Prod. 24 (2006) 253. 


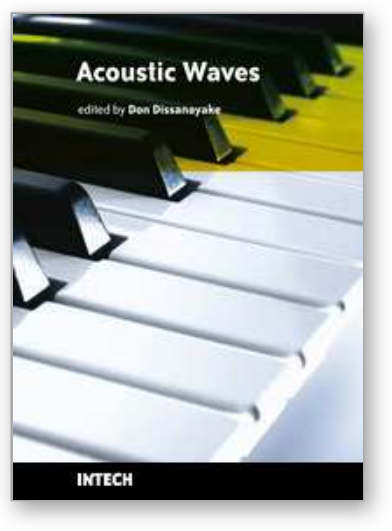

\author{
Acoustic Waves \\ Edited by Don Dissanayake
}

ISBN 978-953-307-111-4

Hard cover, 434 pages

Publisher Sciyo

Published online 28, September, 2010

Published in print edition September, 2010

SAW devices are widely used in multitude of device concepts mainly in MEMS and communication electronics. As such, SAW based micro sensors, actuators and communication electronic devices are well known applications of SAW technology. For example, SAW based passive micro sensors are capable of measuring physical properties such as temperature, pressure, variation in chemical properties, and SAW based communication devices perform a range of signal processing functions, such as delay lines, filters, resonators, pulse compressors, and convolvers. In recent decades, SAW based low-powered actuators and microfluidic devices have significantly added a new dimension to SAW technology. This book consists of 20 exciting chapters composed by researchers and engineers active in the field of SAW technology, biomedical and other related engineering disciplines. The topics range from basic SAW theory, materials and phenomena to advanced applications such as sensors actuators, and communication systems. As such, in addition to theoretical analysis and numerical modelling such as Finite Element Modelling (FEM) and Finite Difference Methods (FDM) of SAW devices, SAW based actuators and micro motors, and SAW based micro sensors are some of the exciting applications presented in this book. This collection of up-to-date information and research outcomes on SAW technology will be of great interest, not only to all those working in SAW based technology, but also to many more who stand to benefit from an insight into the rich opportunities that this technology has to offer, especially to develop advanced, low-powered biomedical implants and passive communication devices.

\title{
How to reference
}

In order to correctly reference this scholarly work, feel free to copy and paste the following:

Se Yeon Oh, Sung-Sun Park and Jongki Hong (2010). Application and Exploration of Fast Gas Chromatography - Surface Acoustic Wave Sensor to the Analysis of Thymus Species, Acoustic Waves, Don Dissanayake (Ed.), ISBN: 978-953-307-111-4, InTech, Available from:

http://www.intechopen.com/books/acoustic-waves/application-and-exploration-of-fast-gas-chromatographysurface-acoustic-wave-sensor-to-the-analysis-

\section{INTECH}

open science | open minds

\author{
InTech Europe \\ University Campus STeP Ri \\ Slavka Krautzeka 83/A
}

\section{InTech China}

Unit 405, Office Block, Hotel Equatorial Shanghai

No.65, Yan An Road (West), Shanghai, 200040, China 
51000 Rijeka, Croatia

Phone: +385 (51) 770447

Fax: +385 (51) 686166

www.intechopen.com
中国上海市延安西路65号上海国际贵都大饭店办公楼 405 单元 Phone: +86-21-62489820

Fax: +86-21-62489821 
(C) 2010 The Author(s). Licensee IntechOpen. This chapter is distributed under the terms of the Creative Commons Attribution-NonCommercialShareAlike-3.0 License, which permits use, distribution and reproduction for non-commercial purposes, provided the original is properly cited and derivative works building on this content are distributed under the same license. 